https://doi.org/10.48009/2_iis_2008_56-62

\title{
SOCIAL PRESENCE, PERSONALITY TYPES, AND IT-SUPPORTED TEACHING METHODS
}

\author{
Kamal Hingorani, Alabama State University, khingorani@alasu.edu
}

\begin{abstract}
The purpose of the study is to examine how students manifest social presence in IT-supported teaching methods. Specifically, the research examined how students' psychological type, as measured by the Myers-Briggs Type Indicator, affects their perception of social presence in a specific IT-supported teaching method. Findings revealed that extraverts felt a higher perception of social presence than introverts. A similar difference was found on the personality dimension of thinking/feeling. These findings have implications for both educators and students as the world moves towards teaching and learning through increased use of IT-supported teaching methods.
\end{abstract}

Keywords: Information Technology (IT), Social Presence, IT-supported Teaching Methods, Psychological Type, and Personality Type.

\section{INTRODUCTION}

During the last decade, Information Technology (IT) and the Internet have significantly changed the way learning is delivered and facilitated in educational settings [3]. Advocates of IT-supported instruction are largely positive and optimistic about the potential of such teaching methods. According to Bibeau [4], teaching and learning functions are inherently social endeavors and it is beneficial to understand the various effects of the psychological distance between instructors and the students. Social presence, the degree to which a medium permits user to experience others as being psychologically present [14, p. 532], has been found to affect student perceived learning in IT-supported teaching methods [34]. Social presence has also been found to increase the satisfaction of students' online experience [26] and leads to greater emotional satisfaction through a sense of well-being in the classroom environment [35].

This research examines how students manifest social presence in IT-supported teaching methods. Specifically, the research examined how students' personality and psychological type, as measured by the Myers-Briggs Type Indicator, affects their perception of social presence in a specific ITsupported teaching method.

\section{THE IT-SUPPORTED TEACHING METHOD}

The teaching method used in this study was an adaptation of the Written Case Study, which today is a well established teaching method in business schools across the U.S. for teaching not only graduate level courses but also senior-level undergraduate courses. A written case typically is a record of a business issue which actually has been faced by business executives, together with surrounding facts, opinions, and prejudices upon which executives' decisions have to depend. These real and particularized cases are then presented to students for considered analyses, open discussion, and final discussion as to the type of action that should be taken.

Information Technology (IT) provides alternatives for bringing real-world cases to the classroom. An executive can now present a case to the classroom, from his or her own office, using easily accessible information technologies. One such method was used to present live-cases to students at a major South Eastern University. This IT-supported method was used for teaching project management to senior-level undergraduate students. The method was used for two successive academic-semesters for teaching project management to business and engineering students.

The classroom for presenting the IT-based case study was equipped with a lecture podium and had connections for telephone, slide, video, and computer displays. The images received from the remote location were projected onto an eight-foot (8') screen using a data projector. Each case study used between five and seven images to describe the project management issue. The students could hear the audio and speak to the project manager.

Each case study lasted for about 50 minutes. The project manager called the classroom from his siteoffice which was located about 200 miles away from the classroom. After introducing himself, he narrated the project management issue with the aid of still images. The project manager used the annotating devices to explain the complexities of the issues involved. The students were allowed to interject if a 
particular issue was not clear or required further clarification. The presentation lasted about 25 minutes. The remaining 25 minutes of the class time were utilized for the interaction between the students and the project manager. The students also used an annotating device to ask questions and seek clarifications.

\section{THE SOCIAL PRESENCE THEORY}

An established theory in social sciences, the social presence theory [39, 44], posits that media differ in social presence or "the degree to which a medium permits user to experience others as being psychologically present" [14, p. 532]. Face-to-face meetings and telecommunication media have been found to be high in social presence while media like electronic-mail, and printed documents are found to be low in social presence [26]. Another theory that parallels this line of reasoning is the information richness theory $[11,43]$. This theory is based on the concept of uncertainty avoidance, which as defined by Hofstede [20, p.83] is "the degree to which members of a society feel uncomfortable with uncertainty and ambiguity." Information Richness of a medium depends upon the interactive nature of the feedback, the personal quality of the source, and the ability to express linguistic innuendos. Daft and Lengel's [12] information richness theory posits that individuals choose media based on task characteristics of equivocality and ambiguity. Equivocality means the existence of multiple and conflicting interpretations about an organizational situation. A media is selected by an individual based on its information richness, which depends on the interactive nature of the feedback, channel type (e.g., body language, facial expression, and tone of the voice), the personal quality of the source, and the ability of the interface innuendos [41]. Face-to-face and telephone communications are rich media while the printed document is a lean medium [26].

Social Presence and Information Richness are used interchangeably forcing one MIS researcher to use the term SPIR (Social Presence and Information Richness) in his study [11].

Social presence is a concept that has gained considerable importance in the MIS literature especially in the context of the effectiveness of communications media. It has been said that face-toface meeting has a higher level of social presence than the written word [26]. There have been few studies conducted to investigate the effect of identifiable individual characteristics on social presence. Some researchers have suggested that a communication medium's social presence (or information richness) is invariant regardless of who is using it or what the context is [14]. Albertson [1, p. 389] noted that people (students and faculty) are regarded as 'black boxes' in the social presence theory.

Social presence has also emerged as an important factor in the field of learning [17]. Many researchers have postulated that the learner's comprehension or retention of knowledge (cognitive learning) as well as their feelings, attitudes, behavior and satisfaction (affective learning) with the course may also be affected by their perception of social presence [21].

It is important for educators to understand the concept of social presence so that they can make effort to maximize social presence in IT-supported teaching methods. This study attempts to examine the effect of individual characteristics - the students' personality and psychological type on social presence in an educational setting

\section{PERSONALITY AND PSYCHOLOGICAL TYPE}

Personality and psychological type are frequently implied to be underlying causes of differences in decision-making processes [45]. One factor that can affect the students' perception of social presence is personality and psychological type. An important and well-accepted test for measuring personality is the Myers-Briggs Type Indicator (MBTI). This psychological test classifies a person on four dimensions, and the four dimensions have been found to have an impact on the preference and performance on selected parameters. The Myers-Briggs Type Indicator (MBTI) is based on Carl Jung's theory that much apparently random variation in human behavior is actually quite orderly and consistent, due to certain basic differences in the way people approach life [6]. The underlying assumption is that every person has a natural preference for one or the other extremes on each of the four indices, analogous to a natural preference for right- or left-handedness. The four indices of the MBTI are:

- Orientation scale: extraversion (E) vs. introversion (I)

- Perception scale: sensing (S) vs. intuition (N)

- Judgment scale: thinking (T) vs. feeling (F)

- Scale of attitude for dealing with outside world: judging (J) vs. perceiving (P).

The Jungian typology does not establish one personality type as superior to the other. Each of the 
personality types has its own strengths and weaknesses.

Extraversion is probably preferred by about two thirds of the population, introversion by one third. Sensing is probably preferred by two thirds to three quarters of the population; but among college students, sensing and intuition are usually closer to 50-50. Thinking and feeling are close to 50-50 overall, but gender plays a significant role: about two thirds of women are feeling types, while at least 60 percent of men appear to be thinking types. Finally, judging is probably preferred by about 55 to 60 percent of the population, perceiving by 40 to 45 percent [5].

\section{THE CONSTRUCT OF SOCIAL PRESENCE}

The construct for social presence has been operationalized by many researchers $[7,41]$. Most researchers have adapted the construct from a series of four experiments conducted during 1972-1974 to measure the social impact of telecommunications media [39]. The items used in this research to measure this concept were: personal, distant, and felt presence of project manager (executive).

\section{SUBJECTS}

A total of 156 students participated in the experiment with 78 students each in the two semesters. Only 107 students participated in both the case studies and they formed the sample for this study. Each IT-supported case study session was conducted twice during each academic semester so as to limit the class size for each session to less than 40 students. One of the classes consisted of business students while the other was a combined class of business and engineering students. No appreciable difference was noticed by the researcher in the kinds or the level of discussions in the two classes.

The demographics of the students who participated in the research are shown in Table I. Thirty-three students were engineering students while 74 students were business students. Thirty-four of the students were females, while the remaining 73 were male. Fifty-six percent of the students were extraverts, 77 percent of the students were sensing, 68 percent of the students were thinking, and 60 percent of the students were judging. The distribution of students among the various personality types was a good representation of the general U.S. population as estimated by Carskadon [5].
Table I - Demographics

\begin{tabular}{|l|c|c|c|}
\hline & $\begin{array}{l}\text { First } \\
\text { Semester }\end{array}$ & $\begin{array}{l}\text { Second } \\
\text { Semester }\end{array}$ & Total \\
\hline Number of students & 78 & 78 & 156 \\
\hline Case Study 1 & 74 & 71 & 145 \\
\hline Case Study 2 & 72 & 58 & 130 \\
\hline Both Case Studies & 61 & 46 & 107 \\
\hline Male & 43 & 30 & 73 \\
\hline Female & 18 & 16 & 34 \\
\hline Engineering Students & 18 & 15 & 33 \\
\hline Business Students & 43 & 31 & 74 \\
\hline Extravert & 30 & 30 & 60 \\
\hline Introvert & 31 & 16 & 47 \\
\hline Sensing & 41 & 41 & 82 \\
\hline Intuition & 20 & 5 & 25 \\
\hline Thinking & 40 & 33 & 73 \\
\hline Feeling & 21 & 13 & 34 \\
\hline Judging & 39 & 25 & 64 \\
\hline Perceiving & 22 & 21 & 43 \\
\hline
\end{tabular}

The students were administered a survey before the first case study for collecting demographic information. After each case study, the students were administered a survey to measure their perception of the social presence. This survey included the three items used to measure the concept of social presence. The students were asked to rate each of the items on a 5-point Likert scale (1=strongly agree, 5=strongly disagree). The MBTI profile for each student was run separately.

The MBTI instrument used for this study included 126 forced-choice questions. The choices are a mixture of word pairs and short statements. Choices are not literal opposites but chosen to reflect opposite preferences on the same dichotomy. The MBTI was administered by the testing center at the university and was completed before the start of the first case study.

\section{ISSUES OF RELIABILITY}

Poor measurement can invalidate any scientific research and most of the criticism of MIS research centers on the issues of reliability and validity [31, 41]. Reliability is the accuracy or precision of a measuring instrument [22]. Nunnally [27] defined reliability as the extent to which measurements are repeatable and that any random influence which tends to make measurement different from occasion to occasion is a source of measurement error (p. 206). The reliability of a measure indicates the stability and consistency with which the instrument is measuring the concept and helps to assess the 'goodness' of a 
measure. Coefficient alpha or Cronbach alpha [10] is one of the most important and pervasive statistics used for verifying the reliability of a construct [9]. A value of 0.70 or higher is considered an indicator of a reliable construct $[9,27]$ although a value of 0.65 is also considered adequate for in some research.

\section{RESULTS}

The Cronbach alpha value for the construct of Social Presence in this research was 0.68 as detailed in Table II.

Table II. Cronbach Alpha

\begin{tabular}{|l|l|l|}
\hline Construct & Items & $\begin{array}{l}\text { Cronbach } \\
\text { Alpha }\end{array}$ \\
\hline $\begin{array}{l}\text { Social } \\
\text { Presence } \\
\text { (3 items) }\end{array}$ & $\begin{array}{l}\text { Felt presence of } \\
\text { Droject Manager, }\end{array}$ & 0.68 \\
\hline
\end{tabular}

* Reverse coded

This research made use of the repeated-measures analyses of variance for analyzing the data. This method was selected because of the fact that the students were measured across two different ITsupported case studies. When several measurements are taken on the same experimental unit, the measurements tend to be correlated with each other. When the measurements represent qualitatively different things this correlation is best taken into account by use of multivariate analysis of variance (MANOVA). When the measurements can be thought of as responses to levels of an experimental factor of interest, the correlation can be taken into account by performing a repeated measures analysis of variance [18, 23, and 50].

The PROC GLM procedure in SPSS 16 for Windows was used to run the repeated measure analysis of variance for this study. The significance level was set at .05 . In repeated measures analysis of variance, the effects of interest are

- within-subject effects (the two different ITsupported case studies) and

- $\quad$ between-subject effects (the four dimensions of MBTI)

The results of the within-subject effects are shown in Table III.
Table III- Tests of Within-Subjects Effects

\begin{tabular}{|c|c|c|c|c|c|}
\hline Source & $\begin{array}{c}\text { Type } \\
\text { III SS }\end{array}$ & df & $\begin{array}{c}\text { Mean } \\
\text { Square }\end{array}$ & $\mathrm{F}$ & Sig. \\
\hline factor1 & .09 & 1 & .093 & .66 & .41 \\
\hline $\begin{array}{l}\text { factor1 * } \\
\text { EXTRAVERT }\end{array}$ & .01 & 1 & .014 & .09 & .75 \\
\hline factor1 * SENSING & .24 & 1 & .245 & 1.73 & .19 \\
\hline factor1 $*$ THINKING & .12 & 1 & .121 & .85 & .35 \\
\hline factor1 $*$ JUDGING & .06 & 1 & .061 & .43 & .51 \\
\hline Error(factor1) & 12.96 & 92 & .141 & & \\
\hline
\end{tabular}

None of the sources shown in Table III indicated any significance, supporting the hypothesis that there was no difference between the mean values of social presence between the two IT-supported case studies.

The results of the between-subject effects are shown in Table IV below.

Table IV: Tests of Between-Subjects Effects

\begin{tabular}{|l|r|r|r|r|r|}
\hline Source & $\begin{array}{c}\text { Type } \\
\text { III SS }\end{array}$ & df & $\begin{array}{c}\text { Mean } \\
\text { Square }\end{array}$ & \multicolumn{1}{c|}{ F } & Sig. \\
\hline Intercept & 451.84 & 1 & 451.84 & 776.04 & .000 \\
\hline EXTRAVERT & 3.95 & 1 & 3.95 & 6.79 & .011 \\
\hline SENSING & .08 & 1 & .08 & .15 & .699 \\
\hline THINKING & 4.68 & 1 & 4.68 & 8.04 & .006 \\
\hline JUDGING & .04 & 1 & .04 & .07 & .780 \\
\hline $\begin{array}{l}\text { Error } \\
\text { (None of the interaction effects were significant and are } \\
\text { not shown in the table) }\end{array}$ \\
\hline
\end{tabular}

There was significant difference on the dimension of Extravert (Extravert/Introvert) and the dimension of Thinking (Thinking/Feeling). To understand the significance of the result, we need to examine the mean values of social presence for the four dimensions of MBTI which are presented in Table V. Here, a lower value of mean suggests a higher level of social presence. 
Table-V: Mean Values for Social Presence

\begin{tabular}{|l|c|}
\hline \multicolumn{1}{|c|}{$\begin{array}{c}\text { MBTI } \\
\text { Dimension }\end{array}$} & $\begin{array}{c}\text { Social } \\
\text { Presence }\end{array}$ \\
\hline 1-Extravert & 2.01 \\
2-Introvert & 2.60 \\
\hline 1-Sensing & 2.33 \\
2-Intuition & 2.25 \\
\hline 1-Thinking & 2.48 \\
2-Feeling & 2.07 \\
\hline 1-Judging & 2.26 \\
2-Perceiving & 2.32 \\
\hline
\end{tabular}

The above table indicates that individuals who are more extraverted, more intuitive, more feeling or more judging experienced a higher level of social presence in this study. The dimension of extravert/introvert and thinking/feeling was statistical significant suggesting that personality type has a significant impact on social presence.

\section{CONCLUSIONS/DISCUSSION}

\section{A. Major Findings}

This study found, as expected, significant relationship between perceived social presence and the students' psychological type as measured by the MBTI. Two of the dimensions- the extravert/introvert and the thinking/feeling dimension - had a statistical significant impact on social presence. A previous study on virtual environment found those individuals who are more sensitive, more feeling or more introverted experience a higher level of presence [36]. None of the cognitive styles reached statistical significance in that study.

The IT-supported teaching method investigated in this study was an adaptation of the case study method. The case study method develops students' skills in group learning, speaking, and critical thinking and is by design more suitable for students with an extraverted personality. The teaching method that was studied in this research was very different that traditional online courses that have formed the basis of most previous studies.

Thinking types like order and logic in their courses and prefer structured experiences and clear goals while feeling types prefer to complete assignments with group projects [30]. The case study method by design should therefore be preferred by the feeling type.

\section{B. Limitations of the Study}

A major limitation of this research is that it explored social presence in the context of a specific ITsupported teaching method that was an adaptation of the written case study method. This study is not representative of all IT-supported teaching methods and as such findings may not be generalizable to other contexts. Future research should investigate these issues with different teaching methods, student populations, and subject areas.

Another limitation of the current study is its reliance on self-reports of social presence through student surveys. Further, this research examined how students' psychological type, as measured by the MBTI affects their perception of social presence in a specific IT-supported teaching method. However, the effects of such perceptions on actual learning were not explored. Such effects should be a focus of future research, as should relationships between specific instructor and student behaviors and actual learning.

\section{Educational Significance}

There have been very few studies that have tried to examine social presence in the case study teaching method. This study may be of significance to educators who use the case study method in their classrooms.

In Fall 2006, an estimated 3.48 million college-going Americans were taking at least one Web class and nearly twenty percent of all U.S. higher education students were taking at least one online course [28]. Most online classes lack face-to-face interaction with classmates and teachers and dropout rates for online courses are often higher than for traditional ones [28]. Raising social presence in online courses is a source of concern for many researchers and educators [26].

Research on online courses have reported on relationships among perceptions of social presence and perceived learning [17, 21, 29, 23, 33, 34, and 36]. The challenge for instructors involved in ITsupported teaching methods is how to improve the students' perception of social presence which in turn will improve students' performance. The findings of the current study provide some direction for enhancing the development of social presence among students participating in IT-supported teaching methods. Instructors developing IT-supported courses need to consider the importance of personality preferences and try to maximize social presence for their methods of delivery and course types. 


\section{REFERENCES}

1. Albertson, L. A. (1980). Trying to Eat an Elephant. Communication Research. 7, 387-400.

2. Anderson, T., Rourke, L, Garrison, D., and Archer, D. (2001) Assessing teaching presence in a computer conferencing context. Journal of Asynchronous Learning Networks 5(2): 2001.

3. Aragon, Steven R. (2003) New Directions for Adult and Continuing Education, v2003 n100 p57-68 Win 2003

4. Bibeau, S. (2001). Social Presence, Isolation, and Connectedness in Online Teaching and Learning. From the literature to real life. Journal of Instruction Delivery Systems, 15(3), 35-39.

5. Carkadan, T. G. (1994). Student Personality Factors: Psychological Type and the MyersBriggs Type Indicator. In K. W. Princhard and R. M. Sawyer (eds.) Handbook of College Teaching: Theory and Applications. Connecticut: Greenwood Press.

6. Carlyn, M. (1977). An Assessment of the Myers-Briggs Type Indicator. Journal of Personality Assessment. 41, 461-73.

7. Chidambaram, L., and Jones, B. (1993). Impact of Communication Medium and Computer Support on Group Perceptions and Performance: A Comparison of Face-to-Face and Dispersed Meetings. MIS Quarterly. December 1993, 465491.

8. Christophel, D. (1990). The relationship among teacher immediacy behaviors, student motivation, and learning. Communication Education 39(4): 323-240, 1990.

9. Cortina, J. M. (1993). What is Coefficient Alpha? An Examination of Theory and Applications. Journal of Applied Psychology. 78(1), 98-104.

10. Cronbach, L. J. (1951). Coefficient alpha and the internal structure of tests. Psychometrika. 16, 297-334.

11. Daft, R. L., and Lengel, R. H. (1984). Information Richness: A New Approach to Managerial Behavior and Organizational Design. In L.L. Cummings and B.M. Staw (Eds.) Research in Organizational Behavior. Greenwich, CT: Jai Press, 191-233.

12. Daft, R. L., Lengel, R. H., and Trevino, L. K. (1987). The Relationship among Message Equivocality, Media Selection, and Manager Performance. MIS Quarterly. 11(4), 355-366.

13. Danchak, M. M., J. B. Walther, and K. Swan (2001). Presence in mediated instruction: bandwidth, behavior, and expectancy violations. Orlando, FL: Paper presented at the Seventh Annual Sloan-C International Conference on
Online Learning, 2001.

14. Fulk, J., Steinfield, C. W., Scgmitz, J., and Power, G. J. (1987). A Social Information Processing Model of Media Use in Organization. Communication Research. 14 (1987), 520-552.

15. Garrison, D. R (2003) Cognitive presence for effective asynchronous online learning: the role of reflective inquiry, self-direction and metacognition. In J. Bourne \& J. C. Moore (eds.), Elements of Quality Online Education: Practice and Direction, 47-58. Needham, MA: Sloan-C, 2003.

16. Garrison, D. R., M. Cleveland-Innes, and T. Fung. (2004) Student role adjustment in online communities of inquiry: model and instrument validation. Journal of Asynchronous Learning Networks 8(2): 61-74, 2004.

17. Gunawardena, C. and F. Zittle (1997). Social presence as a predictor of satisfaction within a computer mediated conferencing environment. American Journal of Distance Education 11(3): 8-26, 1997.

18. Hays, W (1963) Statistics, Holt, Rinehart and Winston, New York, 1963.

19. Hiltz, S. R. (1994). The Virtual Classroom: Learning without Limits via Computer Networks. Norwood, NJ: Ablex. 1994.

20. Hosftede, G. (1984). Cultural Dimensions in Management and Planning. Asia Pacific Journal of Management. January 1984, 81-99.

21. Jolivette-Jones, B. (2007). Emerging Research Questions: Social Presence and its Relevancy to Cognitive and Affective Learning in an Asynchronous Distance-Learning Environment. In G. Richards (Ed.), Proceedings of World Conference on E-Learning in Corporate, Government, Healthcare, and Higher Education 2007 (pp. 1602-1609). Chesapeake, VA: AACE.

22. Kerlinger, F. N. (1973). Foundations of Behavioral Research. New York: Holt, Rinehart, and Winston Inc.

23. LaTour, S.A., and Miniard, P.W. (1983) The Misuse of Repeated Measures Analysis in Marketing Research. Journal of Marketing Research, 20(1), 45-57.

24. Leh, A. (2001). Computer-mediated communication and social presence in a distance learning environment. International Journal of Educational Telecommunications, 7(2), 109-128.

25. Murray, J. B. (1990). Review of Research on the Myers-Briggs Type Indicator. Perceptual and Motor Skills. 1990, 70, 1187-1202.

26. Newberry, B. (2001). Raising student social presence in online classes. Webnet 2000: World Conference on the WWW and Internet Proceedings. Orlando, Florida, October 23-27, 
2001.

27. Nunnally, J. (1967). Psychometric Theory. New York: McGraw-Hill.

28. Online Nation: Five Years of Growth in Online Learning (2007). Sloan Consortium, 2007.

29. Picciano, A. G. (2002). Beyond student perceptions: Issues of interaction, presence, and performance in an online course. Journal of Asynchronous Learning Networks, 6(1), 21-40.

30. Piirto, Jane (1998) The Myers-Briggs Type Indicator and talented adolescents: Feeling Boys And Thinking Girls: Talented Adolescents And Their Teachers, Proceedings of the CAPT Conference, Orlando, Florida, March 1998.

31. Pinsonneault A., and Kraemer, K. L. (1993). Survey Research Methodology in Management Information Systems: An Assessment. Journal of Management information Systems. 10(2), 75105.

32. Polhemus, L., M. Danchak, A. Assis, and K. Swan. (2004) A cyclic approach to online course design. Paper presented at the Tenth Annual Sloan- $C$ International Conference on Asynchronous Learning Networks, Orlando, FL, November, 2004.

33. Poole, D. M. (2002) Student participation in a discussion-oriented online course: a case study. Journal of Research on Computing in Education 33(2): 162-177, 2000.

34. Richardson, J., \& Swan, K. (2003). Examining social presence in online courses in relation to students' perceived learning and satisfaction. Journal of Asynchronous Learning Networks, 7(1), 68-88.

35. Rourke, L., T. Anderson, D. R. Garrison, and W. Archer (2001). Assessing social presence in asynchronous text-based computer conferencing. Journal of Distance Education 14(2): 50, 2001.

36. Sas, C, Hare, G, and Reilly, R (2004) Presence and task performance: an approach in the light of cognitive style, Cognition, Technology \& Work, Volume 6, Number 1 / February, 2004

37. Shea, P. J., A. M. Pickett and W. E. Pelz. (2003) A follow-up investigation of "teaching presence" in the SUNY Learning Network. Journal of Asynchronous Learning Networks 7(2): 61-80, 2003.
38. Shin, N. (2002). Beyond interaction: The relational construct of 'transactional presence'. Open Learning, 17(2), 121-137.

39. Short, J., Williams, E., and Christie, B. (1976). The Social Psychology of Telecommunications. New York: John Wiley \& Sons.

40. Stacey, E. (2002). Social presence online: Networking learners at a distance. Education and Information Technologies, 7(4), 287-294.

41. Straub, D.W. (1989). Validating Instruments Used in MIS Research. MIS Quarterly. 13 (2), 147-169.

42. Stroupe, C. (2003). Making Distance Presence: The compositional voice in online learning. Computers and Composition, 20, 255-275.

43. Suh, K.S. (1999). Impact of communication medium on task performance and satisfaction: an examination of media-richness theory. Information \& Management, 35, 295-312.

44. Tanis, M. (2003). Cues to Identity in CMC. The impact on Person Perception and Subsequent Interaction Outcomes. Thesis University of Amsterdam. Enschede: Print Partners Ipskamp.

45. Thatcher, Andrew and DeCour, Anthony (2003): Small group decision-making in face-to-face and computer-mediated environments: the role of personality. Behaviour and Information Technology, 22 (3) pp. 203-218.

46. Tu, C. H. On-line learning migration: From social learning theory to social presence theory in CMC environment. Journal of Network and Computer Applications 23(1): 27-37, 2000.

47. Tu, C.H, \& McIsaac, M. (2002). The relationship of social presence and interaction in online classes. American Journal of Distance Education, 16(3), 131-150

48. Walther, J. (1994) Interpersonal effects in computer mediated interaction. Communication Research 21(4): 460-487, 1994.

49. Wegerif, R. (1998) The social dimension of asynchronous learning networks. Journal of Asynchronous Learning Networks 2(1): 34-49, 1998.

50. Winer, B. J. (1971). Statistical Principles in Experimental Designs. Second ed. McGraw-Hill, New York 